\title{
INCREASING OUTPUT AND LOW PUBLICATION RATE OF BRAZILIAN STUDIES PRESENTED AT THE AMERICAN SOCIETY OF CLINICAL ONCOLOGY ANNUAL MEETINGS
}

\author{
Everardo D. Saad, ${ }^{\mathrm{I}}$ Cecília M. A. Pinheiro, ${ }^{\mathrm{I}}$ André L. S. Masson, ${ }^{\mathrm{I}}$ Gustavo \\ Borghesi, ${ }^{\text {P Paulo M. Hoff, }}{ }^{\text {II }}$ Flavio E. Prisco ${ }^{\mathrm{I}}$
}

doi: $10.1590 / \mathbf{S 1 8 0 7 - 5 9 3 2 2 0 0 8 0 0 0 3 0 0 0 0 1}$

Cancer is the second most frequent cause of death, ${ }^{1}$ with nearly half a million individuals in Brazil diagnosed with it every year. ${ }^{2}$ It has been suggested that efforts should be directed at increasing the amount of cancer research performed in Brazil, a country where the epidemiologic burden of the disease is not matched by a proportional increase in related research investments. ${ }^{3}$ Although the amount of cancer research is increasing in Brazil, ${ }^{4}$ there is a general impression that clinical research in particular is gaining substantial momentum. This is largely because pharmaceutical companies and contract research organizations have identified Brazil as an attractive site with rapid patient accrual and high quality data collection. Indeed, several recently published major oncology studies have included a substantial number of patients from Brazil, thus ensuring co-authorship of these articles to Brazilian investigators. ${ }^{5-9}$

It would be interesting to investigate the extent to which the increase in research is related to projects that originate in Brazil, as opposed to instances in which a trial is conceived by international researchers with Brazilian investigators contributing to patient accrual. To that end, we analyzed Brazilian studies presented at American Society of Clinical Oncology (ASCO) Annual Meetings. This venue is considered the largest forum for oncology professionals from all over the world to report the latest advances in cancer research. ${ }^{10}$ Although the main focus of the meeting is on medical oncology, the ASCO Annual Meeting is a venue

IDendrix, Arquitetura da Informação Científica.

ICentro de Oncologia, Instituto de Radiologia, Hospital das Clínicas da Faculdade de Medicina da Universidade de São Paulo - Sao Paulo/SP, Brazil. everardo@dendrix.com.br for research presentations in all areas of clinical oncology. On the other hand, studies on radiation oncology, surgical oncology, pediatric oncology, and hematologic malignancy, although frequently presented at ASCO Annual Meetings, have other important venues for presentation.

We conducted a search of the 16,925 abstracts published in the Program Proceedings of the ASCO Annual Meetings from 2001 through 2005. Studies accepted by the meeting's program committee may be presented in several forms, ranging from plenary and oral sessions to posters. Additionally, approximately $40 \%$ of the studies (termed "publication only") only appear in the Program Proceedings. We defined Brazilian studies as those in which at least twothirds of the involved institutions were from Brazil. For cases in which there were two institutions and one of them was Brazilian, we decided by consensus whether the study also qualified as Brazilian.

We identified 154 Brazilian studies (0.90\%); the main characteristics of these studies are shown in Table 1 . The number of Brazilian studies accepted by the program committee of the ASCO Annual Meeting between 2001 and 2005 (Table 2) showed a statistically significant increase over the 5 year period $(\mathrm{P}=0.011)$. Support from the pharmaceutical industry was declared in seven abstracts, always in association with clinical studies. Two Brazilian studies were selected for oral presentation, 6 were selected for oral discussion by invited speakers (in "poster discussion" sessions), 41 were presented as posters, and 105 (68.2\%) appeared as "publication only". There was no statistically significant trend regarding the proportion of studies in the "publication only" category ( $\mathrm{P}=0.407)$.

Only 26 of the 154 studies (16.9\%) were published in 
Table 1 - Type and subject matter of Brazilian studies $(\mathrm{N}=154)$

\begin{tabular}{lc}
\hline Study Characteristics & N \\
\hline Study type & 117 \\
Clinical investigation & 43 \\
$\quad$ Retrospective & 37 \\
$\quad$ Phase II & 24 \\
$\quad$ Unclassified prospective & 4 \\
Phase I & 2 \\
$\quad$ Randomized or phase III & 44 \\
$\quad$ Other & 23 \\
Basic science & 14 \\
Epidemiologic study & \\
\hline Study subject & 27 \\
Tumor biology & 22 \\
Patient care & 19 \\
Breast cancer & 13 \\
Lung cancer & 13 \\
Gastrointestinal cancer & 11 \\
Genitourinary cancer & 10 \\
Head and neck cancer & 5 \\
Hematologic malignancy & 8 \\
Pediatric oncology & 26 \\
Other & \\
\hline & \\
\hline
\end{tabular}

Table 2 - Absolute number and proportion of Brazilian studies in the period 2001-2005

\begin{tabular}{lrrrrr}
\hline Year & 2001 & 2002 & 2003 & 2004 & 2005 \\
\hline Brazilian & 12 & 26 & 46 & 32 & 38 \\
Total & 3118 & 3024 & 3621 & 3554 & 3608 \\
Percent & 0.384862 & 0.859788 & 1.270367 & 0.900394 & 1.053215 \\
\hline
\end{tabular}

$\mathrm{P}=0.011$

full: 21 in journals indexed in Medline only, 3 in Lilacs only, and 2 in both databases. Twenty-one studies appeared in international journals, and 5 in Brazilian journals. The impact factor, available for 16 of the publications, had a median of 2.040 (range, 0.739 to 4.643 ). Figure 1 shows the Kaplan-Meier estimate of time to full publication. When only published papers are considered, the median time to publication was 13.5 months. Of the 26 published studies, 21 $(80.7 \%)$ appeared in print within 2 years from the presentation of the abstract. The low publication rate did not appear to be due to the short follow-up period, since these rates were $16.7 \%, 30.7 \%, 15.2 \%, 9.3 \%$, and $15.8 \%$ for 2001 through 2005 , respectively $(\mathrm{P}=0.323)$. Univariate analyses comparing

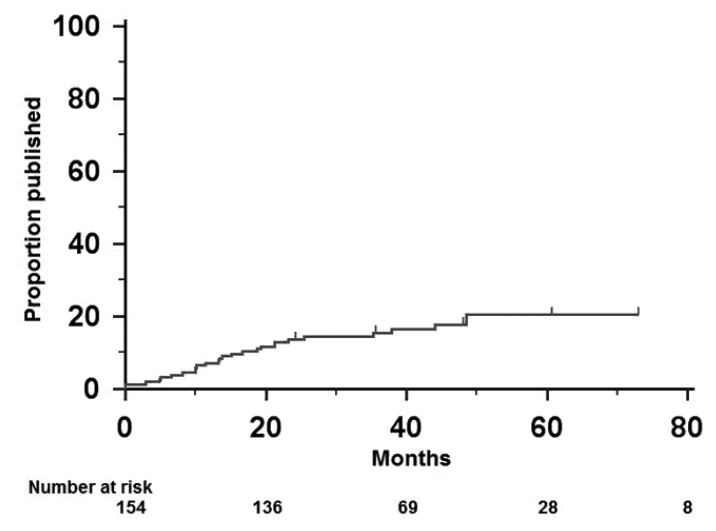

Figure 1 - Time to publication of Brazilian studies initially presented in abstract form between 2001 and 2005 (tick marks represent censoring)

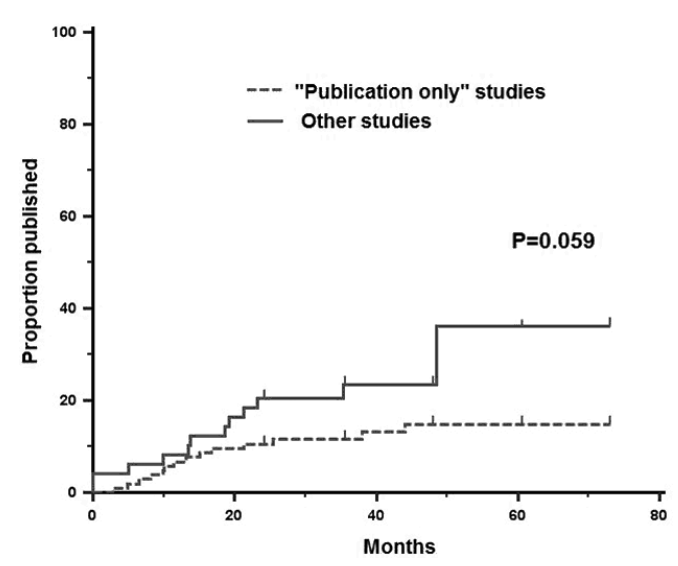

Figure 2 - Time to publication of Brazilian studies accepted for oral presentations, oral discussions and poster presentations, in comparison with abstracts in the "publication only" category (tick marks represent censoring)

abstracts according to both study type and support from the pharmaceutical industry suggested that these variables did not influence the probability of full publication. However, the type of presentation during the meeting had a log-rank $\mathrm{P}$ value of 0.059 when "publication only" studies were compared with the other categories (Figure 2).

A potential limitation of our analysis is the fact that we only looked at studies presented at the ASCO Annual Meeting. Although quality studies may have been presented elsewhere, this seemed unlikely, at least for clinical studies, as other important meetings are less frequently attended by Brazilian investigators because such meetings either focus on specific tumors or are dedicated primarily to basic science. Moreover, radiation oncologists and pediatric oncologists are a smaller group compared with medical oncologists; therefore Brazilian scientific output in these two areas is probably smaller than that originating from medical oncologists. It is also conceivable that quality research 
reports originating in Brazil during these 5 years were submitted for full publication without prior presentation at the ASCO Annual Meeting. This appeared to be of greater concern only in the case of basic science and epidemiologic studies, given that clinical investigators are generally eager to present their data at the ASCO Annual Meeting.

Studies that are similar to ours have been conducted in the past. Goldman and Loscalzo described the fate of 276 randomly selected cardiology abstracts presented at three meetings, and found that $49.6 \%$ of them were published in peer-reviewed journals within a period of 37 to 43 months. ${ }^{11}$ In a study that evaluated abstracts presented at the 1984 ASCO Annual Meeting, using a different methodology than ours, De Bellefeuille et al. found that 115 of 197 abstracts (58\%) accepted for the meeting led to full papers. ${ }^{12}$ Publication rates have also been reported in radiology $\left(35 \%{ }^{13}\right)$ and urology $\left(37.8 \%{ }^{14}\right.$ to $\left.47.3 \%{ }^{15}\right)$, among other disciplines. Compared with these studies, ${ }^{11-16}$ the publication rate of Brazilian abstracts presented at the ASCO Annual Meetings was low. A meta-analysis of 79 reports showed that only $44.5 \%$ of studies initially presented as abstracts or in summary form were published. ${ }^{17}$ Interestingly, this phenomenon of low publication rate is similarly seen for doctoral theses. Younes et al. reviewed the fate of 1,181 doctoral theses presented to the University of Sao Paulo Medical School between 1990 and 2000, and found that more than $50 \%$ of investigators had not published their research within 5 years. ${ }^{18}$

The median interval between abstract presentation and full article publication ranged from 8.6 to 17 months, ${ }^{11,13,15,16}$ with most of these studies published as full papers within 2 years of abstract presentation. ${ }^{14-16}$ In this respect, our findings agreed with those from other investigators, ${ }^{11,13-16}$ suggesting that the time taken in submission, peer review and print was not an explanation for the low publication rate of Brazilian abstracts.

We did not appraise the abstract content as it related to the study result, and were therefore unable to investigate the role of a positive result as a predictor of publication. We were also unable to assess support from the pharmaceutical industry as a possible predictor for publication. Such support was declared in only $4.5 \%$ of the abstracts in our study, which was not sufficient to provide enough power for analysis. However, sponsorship from the pharmaceutical industry has previously been reported to serve as an established predictor of publication of randomized trials presented at the ASCO Annual Meeting. ${ }^{19}$

Our study provides insight into the current contribution of Brazilian studies to international cancer literature. Rodrigues et al. recently provided a quantitative summary of cancer research in Brazil by merging data from Medline and the Institute for Scientific Information. ${ }^{4}$ They found that Brazilian scientific output represented $0.28 \%$ of world cancer research in 1989 and $0.46 \%$ in 1994. In our study, Brazilian abstracts constituted $0.9 \%$ of all studies presented at the ASCO Annual Meetings from 2001 to 2005. Of note, Brazil did not appear in the list of the top 25 countries conducting clinical cancer research between 1995 and 1999. ${ }^{20}$

This analysis indicated an increase in Brazilian cancerrelated scientific output. But it also suggested that the quality of this research is still relatively low, given the high percentage of abstracts in the "publication only" category. Furthermore, only a small proportion of the Brazilian abstracts presented at the ASCO Annual Meeting were later published in indexed journals. Our approach serves as an attempt to answer a major underlying question: to what extent is cancer research conducted in Brazil relevant to Brazilian patients, investigators and society? This study represents a first step towards answering this important question, which should be followed by (amongst other things) the assessment of scientific presentations and publications by Brazilian cancer researchers in a broader perspective (e.g., doctoral theses, published studies regardless of prior abstract presentation, study retrieval from other databases, abstracts presented at other meetings, etc.). These results should be compared with those from other countries and disciplines by the appraisal of study quality, the potential existence of language barriers and other important issues. Although scientific research is clearly increasing in Brazil, ${ }^{21-24}$ with cancer research being one of the areas of increased output, we believe that Brazilian cancer researchers in general, and Brazilian clinical cancer researchers in particular, should strive to enhance the conception, design, analysis and reporting of studies that address questions which are relevant to our patients and our society.

\section{REFERENCES}

1. Brasil. Ministério da Saúde. Datasus. Informações de saúde. Mortalidade - Brasil. Available at http://tabnet.datasus.gov.br/cgi/deftohtm.exe?sim/ cnv/obtuf.def (Accessed July 26, 2007).

2. Brasil. Ministério da Saúde. Instituto Nacional de Câncer. Estimativa 2006: Incidência de Câncer no Brasil. Available at http://www.inca.gov. br/estimativa/2006/ (Accessed June 21, 2007).
3. Zago MA. Clinical research in Brazil. Ciência \& Saúde Coletiva 2004; 9: 363-74

4. Rodrigues PS, Fonseca L, Chaimovich H. Mapping cancer, cardiovascular and malaria research in Brazil. Braz J Med Biol Res. 2000;33:853-67. 
5. Fossella F, Pereira JR, von Pawel J, Pluzanska A, Gorbounova V, Kaukel E, et al. Randomized, multinational, phase III study of docetaxel plus platinum combinations versus vinorelbine plus cisplatin for advanced non-small-cell lung cancer: the TAX 326 study group. J Clin Oncol. 2003:21:3016-24

6. Hanna N, Shepherd FA, Fossella FV, Pereira JR, De Marinis F, von Pawel J, et al. Randomized phase III trial of pemetrexed versus docetaxel in patients with non-small-cell lung cancer previously treated with chemotherapy. J Clin Oncol. 2004;22:1589-97.

7. Piccart-Gebhart MJ, Procter M, Leyland-Jones B, Goldhirsch A, Untch M, Smith I, et al. Trastuzumab after adjuvant chemotherapy in HER2positive breast cancer. N Engl J Med. 2005;353:1659-72.

8. Shepherd FA, Rodrigues Pereira J, Ciuleanu T, Tane H, Hirsh V, Thongprasert $\mathrm{S}$, et al. Erlotinib in previously treated non-small-cell lung cancer. N Engl J Med. 2005;353:123-32.

9. Thatcher N, Chang A, Parikh P, Rodrigues Pereira J, Ciuleanu T, von Pawel J, et al. Gefitinib plus best supportive care in previously treated patients with refractory advanced non-small-cell lung cancer: results from a randomised, placebo-controlled, multicentre study (Iressa Survival Evaluation in Lung Cancer). Lancet. 2005;366:1527-37.

10. Puglisi F, Andreetta C, Fasola G. Highlights from the 42nd annual meeting of the American Society of Clinical Oncology Atlanta, GA, USA, 2-6 June 2006. Expert Opin Pharmacother 2006;7:2309-2318.

11. Goldman L, Loscalzo A. Fate of cardiology research originally published in abstract form. N Engl J Med. 1980;303:255-9.

12. De Bellefeuille C, Morrison CA, Tannock IF. The fate of abstracts submitted to a cancer meeting: factors which influence presentation and subsequent publication. Ann Oncol. 1992;3:187-91.

13. Bydder SA, Joseph DJ, Spry NA. Publication rates of abstracts presented at annual scientific meetings: how does the Royal Australian and New Zealand College of Radiologists compare? Australas Radiol. 2004:48:25-8
14. Ng L, Hersey K, Fleshner N. Publication rate of abstracts presented at the annual meeting of the American Urological Association. BJU Int. 2004;94:79-81.

15. Autorino R, Quarto G, Di Lorenzo G, De Sio M, Damiano R. Are abstracts presented at the EAU meeting followed by publication in peerreviewed journals? A critical analysis. Eur Urol. 2007;51:833-40.

16. Papagikos MA, Rossi PJ, Lee WR. Publication rate of abstracts from the annual ASTRO meeting: comparison with other organizations. J Am Coll Radiol. 2005;2:72-5.

17. Scherer RW, Langenberg P, von Elm E. Full publication of results initially presented in abstracts. Cochrane Database Syst Rev. 2007:MR000005.

18. Younes RN, Deheinzelin D, Birolini D. Graduate education at the faculty of medicine of the University of Sao Paulo: quo vadis? Clinics. 2005;60:6-8.

19. Krzyzanowska MK, Pintilie M, Tannock IF. Factors associated with failure to publish large randomized trials presented at an oncology meeting. Jama. 2003;290:495-501.

20. Grossi F, Belvedere O, Rosso R. Geography of clinical cancer research publications from 1995 to 1999. Eur J Cancer. 2003;39:106-11.

21. Pinheiro-Machado R, De Oliveira PL. The Brazilian investment in science and technology. Braz J Med Biol Res. 2001;34:1521-1530.

22. Coura JR, Willcox Lde C. Impact factor, scientific production and quality of Brazilian medical journals. Mem Inst Oswaldo Cruz. 2003;98:293-297.

23. Bressan RA, Gerolin J, Mari JJ. The modest but growing Brazilian presence in psychiatric, psychobiological and mental health research: assessment of the 1998-2002 period. Braz J Med Biol Res. 2005;38:649-59.

24. Nitrini R. The scientific production of Brazilian neurologists: 1995-2004. Arq Neuropsiquiatr. 2006;64:538-42. 